\title{
Control and prevention of tuberculosis in the United Kingdom: Code of Practice 2000
}

${ }^{\star}$ Subcommittee comprising Peter Ormerod, Royal Infirmary Blackburn

(Chairman, Joint Tuberculosis

Committee); Craig Skinner, Heartlands Hospital, Birmingham; John Moore-Gillon, St Bartholomew's and The Royal London Hospitals, London; Peter Davies, Aintree University Hospital, Liverpool; Mary Connolly, Chest Clinic, Birmingham (representing Royal College of Nursing Tuberculosis Special Interest Group); Virginia Gleissberg, Chest Clinic, Newham, London (representing Royal College of Nursing Tuberculosis Special Interest Group); John Watson, Public Health Laboratory Service Communicable Disease Surveillance Centre, London (representing Faculty of Public Health Medicine); Anton Pozniak, Chelsea and Westminster Hospital, London (representing Medical Society for the Study of Venereal Diseases); Ruth Gelletlie, Bradford (representing the Public Health Medicine Environmental Group); Ann Cockcroft, Occupational Medicine Department, Royal Free Hospital, London (co-opted); Francis Drobniewski, Director PHLS Mycobacterium Reference Unit, London (co-opted); Jane Leese, Department of Health, London.

Correspondence to: Professor L P Ormerod, Department of Respiratory Medicine, Blackburn Royal Infirmary, Blackburn BB2 3LR, UK

admin1@brit-thoracic.org.uk

Received 2 April 2000 Returned to authors 20 June 2000

Revised version received 27 July 2000

Accepted for publication

22 August 2000

Joint Tuberculosis Committee of the British Thoracic Society*

\begin{abstract}
Background-The guidelines on control and prevention of tuberculosis in the United Kingdom have been reviewed and updated.
\end{abstract}

Methods-A subcommittee was appointed by the Joint Tuberculosis Committee (JTC) of the British Thoracic Society to revise the guidelines published in 1994 by the JTC, including representatives of the Royal College of Nursing, Public Health Medicine Environmental Group, and Medical Society for Study of Venereal Diseases. In preparing the revised guidelines the authors took account of new published evidence and graded the strength of evidence for their recommendations. The guidelines have been approved by the JTC and the Standards of Care Committee of the British Thoracic Society.

Recommendations-Tuberculosis services in each district should have staffing and resources to fulfil both the control and prevention recommendations in this document and to ensure adequate treatment monitoring. Notification of tuberculosis is required for surveillance and to initiate contact tracing (where appropriate). The following areas are discussed and recommendations made where appropriate: (1) public health law in relation to tuberculosis; (2) the organisational requirements for tuberculosis services; (3) measures for control of tuberculosis in hospitals, including segregation of patients; (4) the requirements for health care worker protection, including HIV infected health care workers; (5) measures for control of tuberculosis in prisons; (6) protection for other groups with potential exposure to tuberculosis; (7) awareness of the high rates of tuberculosis in the homeless together with local plans for detection and action; (8) detailed advice on contact tracing; (9) contact tracing required for close contacts of bovine tuberculosis; (10) management of tuberculosis in schools; (11) screening of new immigrants and how this should be performed; (12) outbreak contingency investigation; and (13) BCG vaccination and the management of positive reactors found in the schools programme.

(Thorax 2000;55:887-901)
Keywords: tuberculosis; BTS guidelines; code of practice

Introduction/evidence criteria

Since publication of the previous control and prevention guidelines in $1994^{1}$ new data have become available in a number of areas, particularly in infection control, bovine tuberculosis, and the risks of transmission of tuberculosis during air travel which have brought requests for advice. The epidemiology of tuberculosis in Britain has continued to change in recent years.

The numbers of notified cases in England and Wales, which had declined to 5085 in 1987, rose to 5798 in 1992 and 6087 in 1998. The increases have been greatest in urban areas, particularly in London, whereas the decline has continued in most rural areas. ${ }^{2}$ The 1998 National Survey of Tuberculosis in England and Wales confirmed a continuation of the trend for increasing numbers of cases in minority ethnic groups such as those of Indian subcontinent and black African origin. ${ }^{3}$ Notification rates in these groups remain very high. In $1998,56 \%$ of reported cases were in people not born in the United Kingdom. HIV continues to contribute to tuberculosis case numbers: at least $3.0 \%$ of tuberculosis cases in 1998 were estimated to be HIV infected. Drug resistance remains an important issue although rates have not risen in recent years. ${ }^{4}$ In $1998,6.1 \%$ of initial isolates in the United Kingdom were resistant to isoniazid and $1.3 \%$ were multidrug resistant (PHLS unpublished data (Mycobnet)). The Joint Tuberculosis Committee (JTC) of the British Thoracic Society (BTS) has reviewed these new and previous data to produce this updated advice. No category A data using recognised criteria $^{5}{ }^{6}$ (table 1) are available, category $\mathrm{B}$ recommendations are highlighted throughout the text, and all other recommendations should be regarded as of category $\mathrm{C}$ level.

\section{Notification/surveillance}

All forms of tuberculosis are compulsorily notifiable under the Public Health (Control of Disease) Act 1984. The doctor making or suspecting the diagnosis is legally responsible for notification. A decision to commence treatment (but not chemoprophylaxis) indicates a 
Table 1 Levels of evidence and grading of recommendations (based on $A H P C R^{5}{ }^{6}$ )

\begin{tabular}{|c|c|}
\hline Level & Type of evidence \\
\hline Ia & $\begin{array}{l}\text { Evidence obtained from meta-analysis of randomised } \\
\text { controlled trials }\end{array}$ \\
\hline $\mathrm{Ib}$ & $\begin{array}{l}\text { Evidence obtained from at least one randomised } \\
\text { controlled trial }\end{array}$ \\
\hline IIa & $\begin{array}{l}\text { Evidence obtained from at least one well designed } \\
\text { controlled study without randomisation }\end{array}$ \\
\hline $\mathrm{IIb}$ & $\begin{array}{l}\text { Evidence obtained from at least one other type of well } \\
\text { designed quasi-experimental study }\end{array}$ \\
\hline III & $\begin{array}{l}\text { Evidence obtained from well designed } \\
\text { non-experimental descriptive studies such as } \\
\text { comparative studies, correlation studies, and case } \\
\text { controlled studies }\end{array}$ \\
\hline IV & $\begin{array}{l}\text { Evidence obtained from expert committee reports of } \\
\text { opinions and/or clinical experiences of respected } \\
\text { authorities }\end{array}$ \\
\hline Grade & Type of recommendations \\
\hline A (levels Ia, Ib) & $\begin{array}{l}\text { Requires at least one randomised controlled trial as } \\
\text { part of a body of literature of overall good quality and } \\
\text { consistency addressing the specific recommendation }\end{array}$ \\
\hline B (levels IIa, IIb, III) & $\begin{array}{l}\text { Requires availability of well conducted clinical studies } \\
\text { but no randomised clinical trials on the topic of } \\
\text { recommendation }\end{array}$ \\
\hline C (level IV) & $\begin{array}{l}\text { Requires evidence from expert committee reports or } \\
\text { opinions and/or clinical experience of respected } \\
\text { authorities. Indicates absence of directly applicable } \\
\text { studies of good quality }\end{array}$ \\
\hline
\end{tabular}

Table 2 Areas to be covered by the local tuberculosis policy

\begin{tabular}{|c|c|}
\hline $\begin{array}{l}\text { - Aims and objectives } \\
\text { - Surveillance } \\
\text { - } \text { Identification of cases } \\
\text { - Notification } \\
\text { - Treatment } \\
\text { - } \text { Oase management } \\
\text { - Hospital infection control } \\
\\
\text { Screening of vulnerable groups (asylum } \\
\text { seekers, refugees, homeless people, etc) }\end{array}$ & $\begin{array}{l}\text { - Contact tracing } \\
\text { - Immunisation including neonatal policy } \\
\text { - Occupational health } \\
\text { - } \text { Erisons and other institutions } \\
\text { - Monitoring and training } \\
\text { - Health education } \\
\text { - Provision of adequate resources } \\
\text { - } \text { Cosearch and audit } \\
\text { investigation }\end{array}$ \\
\hline
\end{tabular}

level of suspicion which should trigger notification for all forms of tuberculosis.

Notification must be made to the local "proper officer", usually the Consultant in Communicable Disease Control (CCDC) in England and Wales or the equivalent in Scotland (Director of Public Health/ Consultant in Public Health (CDEH)) and Northern Ireland. Notification must include those with concomitant HIV infection. ${ }^{7}$ If a case is subsequently shown not to be tuberculosis, denotification preferably by letter should be carried out. ${ }^{7}$ The purpose of notification is twofold. Firstly, notification triggers contact tracing procedures (see below) and therefore it is vital that all cases, including cases of active tuberculosis diagnosed after death, are notified. Undernotification of tuberculosis is well documented. ${ }^{89}$ Failure to notify could lead to failure to screen close contacts. This could result in contacts with active disease requiring treatment or those who are eligible for BCG or chemoprophylaxis being denied the appropriate intervention. Apart from the health consequences of this failure, such circumstances could lead to an action for medical negligence. Additionally, in some districts notification triggers input of specialist nursing services to individual case management.

The second purpose of notification is to provide surveillance data to detect outbreaks and monitor epidemiological trends so that preventive and treatment services can be planned and targeted appropriately and effectiveness of interventions monitored. Since January 1999 a national programme of enhanced surveillance has been running in England and Wales and Northern Ireland joined the scheme from January 2000. Scotland also began enhanced tuberculosis surveillance from January 2000. In many health districts the form for the enhanced surveillance acts as the notification. Participating in enhanced surveillance is strongly supported by the JTC as it will allow continuous monitoring of numbers of cases, types of disease, and geographical distribution and will ultimately form the basis for regular outcome monitoring. It will, however, need to be appropriately resourced. Detailed advice on notification and improving notification rates is available. $^{7}$

\section{Public health law}

Compulsory treatment is not allowed but in exceptional circumstances it may be necessary to consider compulsory admission of a patient who is causing serious risk of infection to others. ${ }^{10}$ Compulsory admission is only possible where the person has infectious tuberculosis of the respiratory tract. Clearly this is not the kind of action to be undertaken lightly as it involves depriving someone of his or her liberty. The CCDC or equivalent and tuberculosis clinician will want to discuss possible invocation of the law with the legal department of their local authority. If the person has to be detained it will be necessary to obtain a magistrate's order for admission (Section 37) and another order for detention (Section 38). ${ }^{10}$ Compulsory medical examination can also be required (Section 35) under the Public Health Act. ${ }^{10}$

\section{Organisation of tuberculosis services}

The responsibility for the local prevention and control of tuberculosis rests in England and Wales with the CCDC and in Scotland with the CDEH. All health authorities should have a written agreed "integrated" policy outlining all tuberculosis control and prevention measures to be implemented in the local area (table 2). ${ }^{11}$

Adequately staffed, resourced, and trained microbiological services are crucial to an effective tuberculosis programme. Every endeavour should be made to obtain samples for microscopic examination and culture. Microscopic examination of sputum permits identification of infectious cases and culture allows mycobacterial identification and drug susceptibility testing. Samples sent for histological examination must also be sent for microbiological examination as fresh or frozen material without formalin. In most hospitals the microbiologist is also the hospital infection control doctor and laboratory data will facilitate this role in determining infectivity and the scope of an outbreak investigation, for example.

All patients with tuberculosis should be under the care of physicians and nurses with full training in the disease. ${ }^{12}$ Successful treatment of tuberculosis relies on a strong working relationship between a consultant physician, who manages the clinical aspects of the 
patient's treatment, and the specialist nurse, who provides continuity of care through individualised care packages. [B]

The roles and responsibilities of all those involved in the prevention and control of tuberculosis, including doctors, nurses, microbiologists and CCDCs, should also be defined in the local policy. In areas with low notification rates health visitors may undertake tuberculosis nursing duties as part of their role and it is essential for them also to have access to training, advice, and information regarding tuberculosis. In areas where there is no dedicated tuberculosis nurse/health visitor it is necessary for the physician to be more involved with supervision of the broader aspects of tuberculosis control such as treatment support and contact tracing.

Specialist tuberculosis nurses and health visitors, working as higher level practitioners, ${ }^{13}$ are key to the prevention and control of tuberculosis. ${ }^{14}$ There is, however, a disparity in the level of clinical responsibility and practice among specialist tuberculosis nurse/health visitors nationally. This is not only influenced by serious under-resourcing in many areas, ${ }^{15}$ but also, critically, by the significant variation in the definition of the role. ${ }^{16}$ Since 1988 the JTC has recommended a minimum of one full time tuberculosis nurse/health visitor for every 50 notifications per annum plus full clerical support. ${ }^{1112}$ A recent audit of staffing levels in 42 districts of the UK with incidence levels above 15/100 000 per annum showed that only six districts met these requirements. ${ }^{15}$ The JTC and the UK Departments of Health continue to recommend these minimum staffing levels. ${ }^{11}$ Adequate clerical support is particularly important to release professional nurses and doctors to do what they are trained to do.

While treatment is largely standardised, tuberculosis services must plan care individually for tuberculosis patients who inevitably require different levels of assistance and supervision varying from minimum monthly review to thrice weekly directly observed therapy (DOT). For some patients it will be more appropriate for the nurse to work collaboratively with other professionals and care agencies in the administration of DOT. ${ }^{12}$ However it is administered, the use of DOT, as recommended for those at risk of non-adherence, has dramatically increased the workload of the specialist tuberculosis nurse/health visitor. Tuberculosis services must promote access to a client group which is increasingly difficult to reach and, most importantly, must provide opportunities to ensure adherence to prescribed treatment, a factor recognised as the key to a successful outcome to treatment. ${ }^{17}$

The distribution of tuberculosis in England and Wales continues to vary markedly by geographical area. ${ }^{2}$ The tuberculosis services in each district must reflect not only the absolute number and rates, but the case load profile including the proportion of those born abroad, levels of homelessness and other factors affecting both transmission and case management, and the proportion of patients requiring greater support and/or on DOT.
Workload and cost analyses should be carried out at district level to establish appropriate staffing and resource requirements. Health authorities, primary care groups (future primary care trusts), and NHS trusts should agree contracts for the control and treatment of tuberculosis in accordance with this Code of Practice, recommendations of the Interdepartmental Working Group on Tuberculosis for the prevention and control of tuberculosis at a local level, ${ }^{11}{ }^{18}$ and of the JTC of the BTS on chemotherapy and management of tuberculosis in the UK. ${ }^{12}$

\section{Control of tuberculosis in hospitals}

Although the treatment of tuberculosis should be undertaken in the patient's home whenever possible, some patients will need admission because of the severity of illness, adverse effects of chemotherapy, for social reasons, or for investigations to establish the diagnosis. Tuberculosis is transmitted through the aerosol route. Adults with non-pulmonary tuberculosis can be nursed on a general ward although aerosol generating procedures such as abscess or wound irrigation may necessitate patient isolation. Patients with suspected pulmonary tuberculosis should initially be admitted to a single room vented to the air outside until their sputum status is known and risk assessments are made. Risk assessments for the likelihood of infectiousness and multidrug resistant tuberculosis (MDR-TB) should be made (box 1), taking into account the immune status of other patients on the ward (fig 1). ${ }^{18}$

Patients whose bronchial washings are smear positive should be managed as if non-infectious unless (1) the sputum is also smear positive or becomes so after bronchoscopy, (2) they are on a ward with immunocompromised patients, or (3) they are known or suspected of having MDR-TB (see below). Patients whose induced sputum is smear positive should be managed as infectious. Children with tuberculosis and their visitors should be segregated from the rest of the ward until the visitors have been screened to exclude them as a source of infection. ${ }^{19}$ Only those, including young children, who have already been in close contact with the patient before diagnosis should be allowed to visit while the patient is still considered infectious. Marked crockery and separate washing up facilities are unnecessary, and no special precautions are needed for bed linen, books, etc. Sputum specimens and other respiratory specimens should be sent

- Previous drug treatment for tuberculosis

- Contact with a case of known MDR-TB

- HIV infected

- Failure of clinical response on treatment

- Prolonged sputum smear or culture positive while on treatment (smear positivity at 4 months or culture positivity at 5 months)

Box 1 Factors to consider for increased risk of multidrug resistant tuberculosis (MDR-TB). 


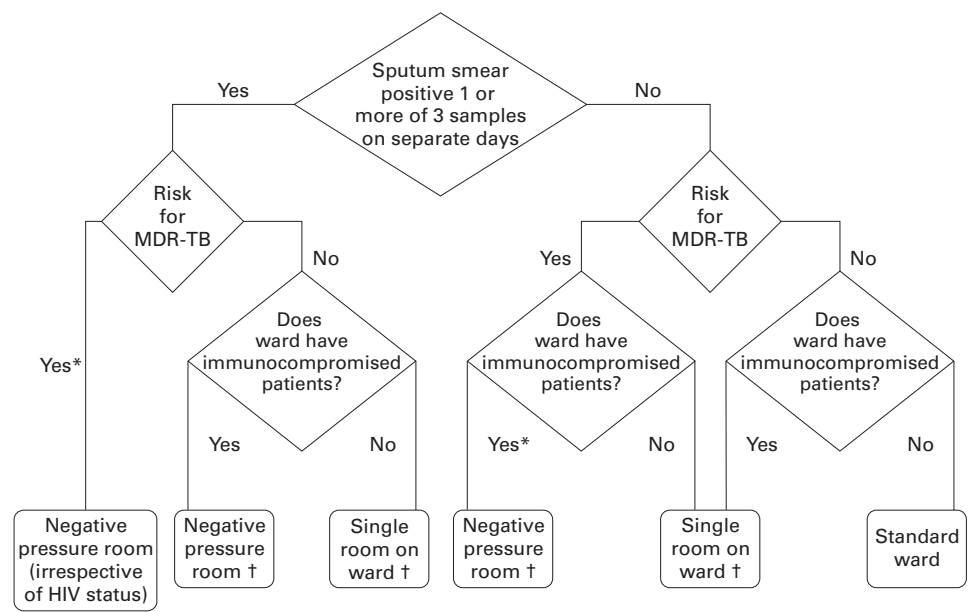

Figure 1 Risk assessment of infectivity and other factors. ${ }^{*}$ Molecular tests for identification of Mycobacterium tuberculosis and rifampicin resistance strongly recommended. If previous treatment for tuberculosis or contact with multidrug resistant tuberculosis (MDR-TB), molecular test for rifampicin resistance mandatory; if rifampicin resistance treat/isolate as $M D R-T B$. inform the patient. Model letters for these purposes are set out in the Appendix.

If the length of stay of the index case was for more than a day or two, and the other patients are known to be unusually susceptible to infection, such individuals should have their risk assessed even if they did not share the same bay. Where the index case is subsequently identified as having MDR-TB, more stringent procedures for contact tracing may be necessary. ${ }^{18}$

A repeat risk assessment should also be made if investigation of the household contacts of the index case has an unusually high yield. If a patient does not fall into either of the above two categories, no action or screening of any kind is required.

No two episodes of this kind are likely to be identical in all respects, and narrowly drawn guidelines are thus inappropriate. In cases of doubt, further advice should be sought from individuals experienced in the field.

in plastic bags and labelled "biohazard". Disposal of infected material should be by incineration. Fumigation of rooms that have housed patients with tuberculosis is unnecessary. Any staff members who attend the patient in a routine manner are not at special risk. However, because of the more serious consequences of infection, those attending confirmed or suspected infectious MDR-TB patients should use dust mist-fume masks meeting the 1992 Personal Protective Equipment (EC Directive) Regulations. ${ }^{18}$ Staff in casual contact with a case of smear positive tuberculosis should be reassured and reminded of the possible symptoms of tuberculosis to report. Staff who have undertaken mouth-to-mouth resuscitation without appropriate protection, prolonged care of a high dependency patient, or repeated chest physiotherapy on a patient with undiagnosed respiratory tuberculosis should be managed as close contacts (see below).

If an individual on an open ward is diagnosed as having infectious tuberculosis, the risk of other patients being infected is likely to be small. Decisions about appropriate action should take into account the degree of infectivity, the duration before the infectious individual was isolated, the proximity of contact, and whether other patients were unusually susceptible to infection.

(1) If another patient's exposure was sufficiently extensive to be equivalent to a household contact, or the exposed patient is known to be particularly susceptible to infection, they should be managed as equivalent to a household respiratory contact (see later).

(2) In general, patients in the same bay (rather than the whole ward) should be regarded as at risk, but only if the index case was coughing and was present in the bay for more than 8 hours before isolation. It is sufficient to document the possible exposure in the records, to inform the contact's general practitioner and consultant, and to
INFECTIOUSNESS AND SEGREGATION OF PATIENTS WITH TUBERCULOSIS

HIV related and drug resistant tuberculosis are separate issues. However, preventing the transmission of tuberculosis infection to HIV infected (and other immunocompromised) individuals and from patients with drug resistant (especially multidrug resistant) tuberculosis involves similar considerations so they are covered here together.

Patients with smear positive disease not known or

Such patients usually become non-infectious after two weeks of treatment including rifampicin and isoniazid ${ }^{12}$ and remain so if regular adequate chemotherapy is continued, even smears. In hospitals and other institutional settings, segregation for reasons of infectiousness is generally only required for two weeks. ${ }^{20}{ }^{21}$ Barrier nursing is unnecessary and staff need not wear gowns. Data support the long standing recommendation that the routine wearing of masks is unnecessary. It is not necessary to separate an infectious person on treatment from other household members. ${ }^{22}$ [B]

Additional considerations in HIV settings

HIV infected and tuberculosis patients should not be mixed. In settings where other patients may be infected with HIV or otherwise immuof pulmonary tuberculosis should be considered as potentially infectious on every admission until proved otherwise and segregated accordingly. Such patients with potentially infectious tuberculosis should be segregated from other immunocompromised patients by admission to a single room in a separate ward or to a negative pressure ventilation room if on the same ward with air pressure continuously or automatically measured. ${ }^{15}$ [B]

For all patients in a HIV ward, aerosol generating procedures such as bronchoscopy, sputum induction, or nebuliser treatment suspected to have MDR-TB though bacilli might still seen in sputum nocompromised, suspected or confirmed cases 


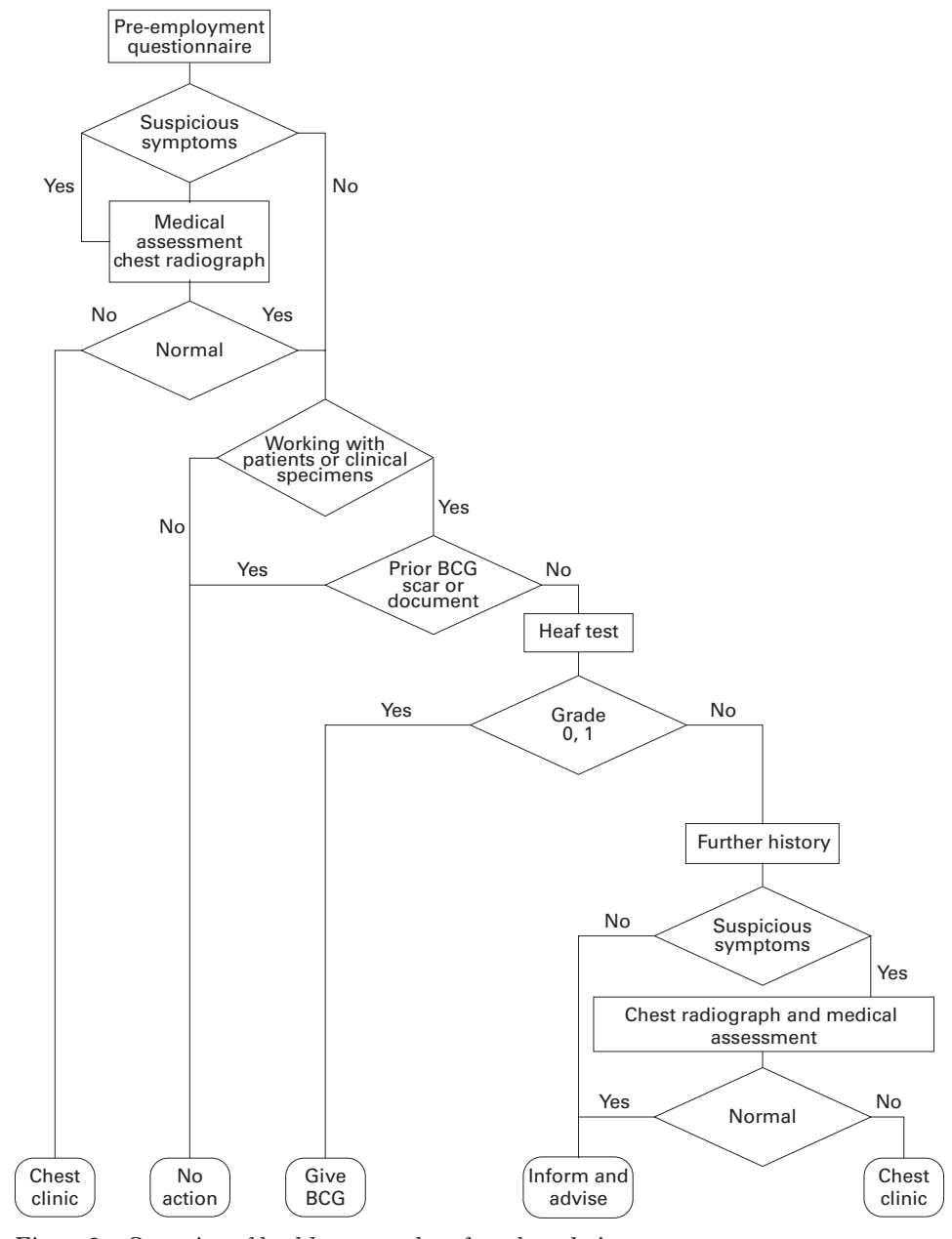

Figure 2 Screening of health care workers for tuberculosis.

should be carried out in an appropriately engineered and ventilated area.

Criteria for the cessation of segregation have to be judged individually for each patient but, in an HIV setting, the patient can normally be considered non-infectious if the following criteria are met:

(1) Sputum smear positive cases (a) the patient has had a minimum of two weeks of appropriate multiple drug therapy; and (b) if potentially being moved to accommodation (inpatient or home) with HIV infected or immunocompromised patients to have a minimum of three negative sputum microscopic smears on separate occasions over at least a 14 day period; and (c) shown tolerance to the prescribed treatment and an ability and agreement to adhere to treatment; and either (d) a complete resolution of cough; or (e) definite clinical improvement to treatment-for example, remaining afebrile for one week.

(2) Sputum smear negative cases (three sputum samples on separate days or if no sputum and bacteriology only from bronchoscopy and lavage); (a), c), (d), and (e) above apply.

The bacteriological response to chemotherapy is equally good in HIV infected and non-HIV infected individuals. ${ }^{23} 24$
Infectious patients suspected or known to have $M D R-T B$

MDR-TB is not more virulent or more infectious than other forms of tuberculosis, but the consequences of acquiring disease are much more serious because of the complexities and duration of the required treatment regimens.

(1) All patients with suspected or known infectious MDR-TB should be admitted to a negative pressure ventilation room. If none are available locally the patient must be transferred to a hospital where the facilities, together with a physician experienced in the management of complex drug resistant cases, are available.

(2) Staff and visitors should wear dust/mist masks meeting the 1992 Personal Protection Equipment (EC Directive) Regulations during patient contact while the patient is considered infectious.

(3) The patient should remain in isolation in a negative pressure room until assessed to be non-infectious. This involves the same criteria as for those with HIV and tuberculosis but ideally should also include maintaining isolation until cultures are negative.

(4) The decision to discharge must be discussed with the hospital infection control team, the local microbiologist and the $\mathrm{CCDC} / \mathrm{CDEH}$.

(5) Before a discharge from hospital is made, secure arrangements for the supervision and administration of all antituberculosis therapy should have been made and agreed with the patient and carers.

(6) All treatment either as an inpatient or an outpatient should be fully supervised unless there are exceptional circumstances.

\section{Health care worker protection}

Staff at risk should be protected and measures should be taken to detect tuberculosis in new and existing staff in order to protect their patients and colleagues. The recommendations for new staff are summarised in fig 2 . All staff should be aware of the infection control guidelines for patients with known or suspected tuberculosis. All health care workers are under an overriding ethical as well as a legal duty to protect the health of their patients and maintain confidentiality. Staff with symptoms compatible with tuberculosis should seek advice from occupational health or from their own doctor so that they do not expose patients to infection.

\section{STAFF AT RISK}

Evidence from the late 1980s suggested that the incidence of tuberculosis in health care workers was no higher than in the general population $^{25}$ with the possible exception of mortuary workers. A more recent study found about a twofold increased risk of tuberculosis among health care workers. ${ }^{26}$ Staff protection begins with pre-employment and onemployment measures. It also includes the adoption of safe practices for patient care and methods of detecting tuberculosis infection in 
staff at an early stage. BCG does not confer complete protection and therefore tuberculosis can still occur in vaccinated health care workers.

Pre- and on-employment measures for new employees

Pre-employment and on-employment measures include recording any history of tuberculosis or symptoms of tuberculosis, details of previous BCG vaccination and the presence or absence of a BCG scar, and occasionally tuberculin testing and chest radiography where indicated.

A tuberculin test (usually the Heaf test, table 3 ) is only necessary in new employees who do not have either a definite BCG scar (as recorded by an experienced person) or documentary evidence of a previous BCG. Virtually all those with a BCG scar have a positive tuberculin test even many years later. ${ }^{27}$ Those who have no BCG scar but a documented positive tuberculin test (usually Heaf grade 2 or more) within the last five years do not need the skin test repeating. Data on an upper age limit for the efficacy of BCG vaccination are limited. Most clinical trials of the efficacy of BCG have largely been performed in children and young adults. ${ }^{28} \mathrm{~A}$ meta-analysis in health care workers of median age 23 years at vaccination also provided few data. ${ }^{29}$ Unlike household contacts who have a limited duration of exposure, the risks of exposure in health care workers potentially continue throughout that occupation. On this basis it is recommended that individuals working as health care workers, irrespective of age, who are previously unvaccinated and who are negative or Heaf grade 1 on tuberculin testing, should receive BCG vaccination. It is not necessary to inspect the site after the vaccination (unless as a means of quality control of the technique of administering the BCG). The BCG should only be given by suitably trained personnel. If BCG vaccination is refused, the risks should be explained and the refusal recorded. The importance of reporting possible symptoms of tuberculosis promptly should be re-emphasised. There may be a need to restrict the area of work of staff who refuse to be vaccinated. There is evidence that strongly positive tuberculin skin reactions are common in asymptomatic health care workers and do not indicate active tuberculosis. ${ }^{30-32}$ The requirement for chest radiography should not be based on the tuberculin skin reaction alone, but rather on the presence of symptoms or a history of contact with tuberculosis on careful enquiry. ${ }^{33}$ If the chest radiograph is abnormal, the individual should be referred to a chest physician. If the clinical and chest radiographic examinations reveal no evidence of tuberculosis, then subsequent management should follow that for asymptomatic individuals (fig 2). [B]

In general, asymptomatic individuals with grades 2,3 or 4 positive Heaf tests should be advised that they have encountered the tubercle bacillus in the past and do not require BCG vaccination, but they should also be advised of the implications of the positive test and of the
Table 3 Heaf testing

\begin{tabular}{ll}
\hline Heaf test grade & Reaction \\
\hline Negative & No induration \\
1 & $4-6$ papules \\
2 & Confluent papules form indurated ring \\
3 & Central filling to form disc \\
4 & Disc $>10 \mathrm{~mm}$ with or without blistering
\end{tabular}

The equivalent Mantoux positive levels done with $10 \mathrm{TU}$ $(0.1 \mathrm{ml} 100 \mathrm{TU} / \mathrm{ml}, 1: 1000)$ are $5-14 \mathrm{~mm}$ induration (Heaf 2) and $>15 \mathrm{~mm}$ induration (Heaf 3-4), respectively. ${ }^{12}$

importance of prompt reporting of symptoms suspicious of tuberculosis. [B]

New employees from a country where the annual incidence of tuberculosis is greater than $40 / 100000$ and who have not been screened on entry, in the district of residence, or by a previous employer in Britain, should be screened as described in the section on 'Screening of immigrants'. This should include a chest radiograph and referral to a chest physician for those with a strongly positive tuberculin skin test. Those in groups, or from countries, with a high prevalence of HIV infection, should be considered for HIV testing before BCG vaccination in tuberculin negative individuals. [B]

\section{Staff in employment}

It is uncommon for hospital staff to acquire tuberculosis from patients. ${ }^{34}$ Health care workers have a duty of care to their patients and should be made aware of the importance of prompt reporting of symptoms suspicious of tuberculosis. Various ways of reminding staff about this could be used such as in-house newsletters and displays on national action days. Routine periodic chest radiography is not necessary for any group of NHS staff and is not effective in the detection of tuberculosis. ${ }^{25}$ [B]

\section{Staff with tuberculosis}

When a health care worker is diagnosed with tuberculosis, whether occupationally acquired or not, liaison is important between the treating physician, the occupational health department, and the infection control team. If the worker has been at work while infectious, it is necessary to identify patients and colleagues who have had significant contact and manage them as described in the section on 'Contact tracing procedures'.

MEDICAL AND NURSING STUDENTS, LOCUM AGENCY DOCTORS, AGENCY STAFF, AND CONTRACT ANCILLARY WORKERS

The measures described above apply. Locum agencies and contractors should ensure that suitable screening has been carried out so that locums can provide evidence of this, but ultimately the responsibility lies with the employer.

HIV AND PROTECTION OF HEALTH CARE STAFF AGAINST TUBERCULOSIS

The issues concerning immunocompromised health care workers and tuberculosis were specifically discussed in the recommendations of the Interdepartmental Working Group on 
Tuberculosis. ${ }^{18}$ HIV infection is relevant both to staff immunisation and to the risk of staff contracting tuberculosis in their work.

HIV infected health care workers: pre-employment assessment

HIV infected health care workers must promptly seek and follow expert medical and occupational health advice and not rely on their own assessment of the risk they pose to patients. ${ }^{35}$ If HIV infected health care workers choose to care for HIV infected patients, they should understand that they should not care for patients with infectious tuberculosis as they put themselves at risk and may then put others at risk should they themselves become infected. It is recommended in the UK that BCG vaccination should not be given to individuals known or suspected to be infected with HIV. ${ }^{36}$ Routine screening for HIV infection before BCG vaccination of new staff is not appropriate, but enquiries should include questions to determine whether the individual has a high risk of being immunocompromised and HIV testing offered if appropriate.

\section{$H I V$ infected health care workers already in employment}

The occupational health physician will advise a known HIV infected worker on whether alternative work should be recommended to avoid possible exposure to tuberculosis. If the health care worker already works with HIV infected patients when their HIV status is disclosed, they may choose to continue to work with HIV infected patients. In this case arrangements may need to be made to ensure that he or she is not allowed to care for patients with known or suspected pulmonary tuberculosis. Since so many HIV infected patients are admitted with respiratory symptoms, this will raise practical issues such as implications for staffing and difficulties in maintaining confidentiality.

Whatever their HIV status, staff have a duty of care not to put HIV infected patients or health care workers at risk should they themselves develop tuberculosis. They should therefore understand the symptoms of tuberculosis and seek medical advice immediately should they develop such symptoms, and should not rely on their own assessment of the risk they pose to patients. Recent reports from the UK have described outbreaks of tuberculosis including multidrug resistant strains from patients with HIV infection. ${ }^{37}$ These pose an important potential risk to staff and other patients and proper infection control measures are important. ${ }^{18}$

\section{Tuberculosis in prisons}

Tuberculosis was not common in HM prisons in the early 1990s and transmission within prisons had not been recorded by $1993 .^{38}$ The substantial majority of prisoners are aged under 50 years. They, and most prison officers, should have been protected by BCG vaccination. New staff should be screened as for at risk health care workers (fig 2) and any current staff who have missed such screening should have it carried out in post ${ }^{39}$ and be offered BCG vaccination if tuberculin negative. A high index of suspicion for tuberculosis should be maintained in all prisons with early radiological and bacteriological investigation, including molecular diagnosis, where appropriate. Prisoners are entitled to the same level of care and investigation as the general population under the European Convention on Human Rights. Diagnosed cases should have DOT supervised by a chest physician, and should have the same isolation criteria applied as for other patients (fig 1). Continuation of treatment and supervision are vital when a prisoner is discharged or transferred and this should be ensured by the Prison Service. ${ }^{40}$ Notification of cases to the local CCDC is essential to enable contact tracing. Routine screening of prison populations by radiography is unnecessary.

Other groups working with populations at particular risk of tuberculosis

Probation officers, police officers, community workers, and volunteers who work with patients and prisoners are not normally at risk. Individuals who are at higher risk deemed to be similar to health care workers with clinical contact should be offered similar protection. Volunteers should not normally be required to carry out duties that expose them to infectious cases. Normal contact tracing procedures apply should contact with undiagnosed infectious tuberculosis inadvertently occur.

\section{The elderly in long stay care}

Evidence from some parts of the USA has suggested that residents in homes for the elderly may be at increased risk of tuberculosis. ${ }^{41}$ There is no evidence of such risk from UK data. ${ }^{42}$ A previous history of tuberculosis should be noted on admission. Residents developing symptoms suggestive of tuberculosis should be investigated. If a resident is diagnosed as having infectious tuberculosis, normal contact tracing procedures should apply. As the results of tuberculin testing in the age groups in homes are difficult to interpret, ${ }^{42}$ chest radiography is probably of more value than tuberculin testing at initial screening. If any staff develop symptoms compatible with tuberculosis, early chest radiography is advised. [B]

\section{Schoolteachers and others working with children}

Routine pre-employment screening to exclude active tuberculosis is no longer required. It is important that those working with children should be aware of the symptoms of tuberculosis and attend for early medical examination should they develop possible symptoms.

\section{Homeless persons}

Accurate estimates of the occurrence of tuberculosis in the homeless are difficult to obtain because of problems with definitions of homelessness and the mobility of the population. All available studies point to tuberculosis being a particular problem in this group. The risk is highest in those sleeping rough and visiting temporary shelters; studies in London suggest 
rates of at least 150 times the national average ${ }^{43}$ but populations resident in hostels and other accommodation provided for the statutorily homeless contain disproportionate numbers of individuals in high risk groups for tuberculosis.

Case finding, with early referral of individuals with symptoms suggestive of tuberculosis, is facilitated if all those who work with the homeless have some knowledge of tuberculosis and its usual manifestations, and what to do/who to contact if they suspect a case. This education could be extended to the homeless themselves. Active case finding by, for instance, mass radiography has only been found to be helpful in the UK in populations at the very highest risk. $^{43} 44$

Tuberculosis and homelessness was examined in detail by a Government Interdepartmental Working Group in $1996 .^{45}$ The measures necessary to deal effectively with tuberculosis in the homeless will vary greatly from district to district. We recommend that, as a minimum, information should be collated from the local authority and other local agencies with the aim of estimating the size, locality, and nature of any homeless population. Appropriately targeted and accessible local services, which may need a highly flexible approach to the provision of diagnostic services and the provision of treatment, should then be instituted.

\section{Contact tracing procedures}

Contact tracing and examination is undertaken to detect associated cases, to detect persons infected but without evidence of disease, to identify candidates for BCG vaccination and, in some instances where recent infection has occurred such as in children, to detect a source case and other co-primary cases. Additionally, contact tracing may be a method of assessing and screening a local population with a high incidence of tuberculosis. Contact tracing may also identify geographical linkage of cases prompting cluster investigation.

\section{CLOSE CONTACTS}

These comprise people from the same household sharing kitchen facilities and very close associates such as boyfriend/girlfriend or frequent visitors to the home of the index case. Occasionally a contact at work or in a hospital ward is close enough to be equivalent to a household contact. It is important to consider the lifestyle of an index and/or source case carefully as it may reveal places of close contact other than domestic or occupational, such as homeless shelters, cinemas, bars, clubs, or aircraft.

\section{CASUAL CONTACTS}

These include most occupational contacts. Examination is only necessary if the index case is smear positive and contacts are unusually susceptible-for example, young children or immunocompromised adults - or the index case is considered highly infectious as shown by transmission to more than $10 \%$ of close contacts $^{7}$ or in the circumstances of an outbreak. [B]

Studies suggest that significant exposure in these circumstances ${ }^{46}$ is a cumulative total exceeding eight hours within the same room as an infectious case.

Five contact studies $^{47-51}$ which included a total of 22971 contacts showed that up to $10 \%$ of tuberculosis cases were diagnosed by contact tracing, that disease occurs in about $1 \%$ of contacts, and that it is usually found in the first clinic visit in unvaccinated close contacts of patients with smear positive disease. More recent studies ${ }^{52-54}$ have confirmed a secondary case yield of $1 \%$. In these latter studies examination was largely confined to close contacts (see below). For the three studies taken together, the mean number of contacts examined was 6.5 per index case.

Smear negative pulmonary patients are far less infectious that those who are smear positive. In a recent study of tuberculosis in San Francisco using DNA fingerprinting of patient isolates, ${ }^{55}$ the relative transmission rate from smear negative compared with smear positive patients was estimated to be 0.22 , similar to an estimate of 0.28 from a study using conventional methods. ${ }^{56}$ We continue to recommend screening of close contacts of patients with smear negative pulmonary disease irrespective of their culture results. [B]

Screening of casual contacts is far less productive. In a survey in England and Wales of 56 incidents in each of which more than 100 contacts had been screened, ${ }^{57}$ the yield of cases was only $0.375 \%$ even though, in these incidents, index cases may have been considered particularly infectious or the contacts especially vulnerable. The yield might be expected to be even less in routine practice.

PULMONARY DISEASE

Recommended procedures are shown in fig 3. Only close contacts should be screened initially, but screening should be extended to casual contacts if the criteria set out above are met. [B]

NON-PULMONARY DISEASE

The incidence of tuberculosis among close contacts generally reflects the background incidence in the relevant population subgroup. Routine screening is not recommended. It may be an appropriate local strategy for accessing and screening a high risk population. ${ }^{53}$ Screening of close contacts to detect a source case is also appropriate if the index case has features suggestive of recent infection such as erythema nodosum or meningitis, is HIV infected, or is a child. [B]

If a large contact tracing exercise is planned-for example, in a hospital or a school-we recommend prior rapid confirmation of the diagnosis of tuberculosis (as opposed to non-tuberculous mycobacteriosis) by molecular identification of the smear or culture of the index case. This service is available from, for example, the Mycobacterium Reference Unit in London, the Mycobacterium Reference Laboratory in Edinburgh, or the 


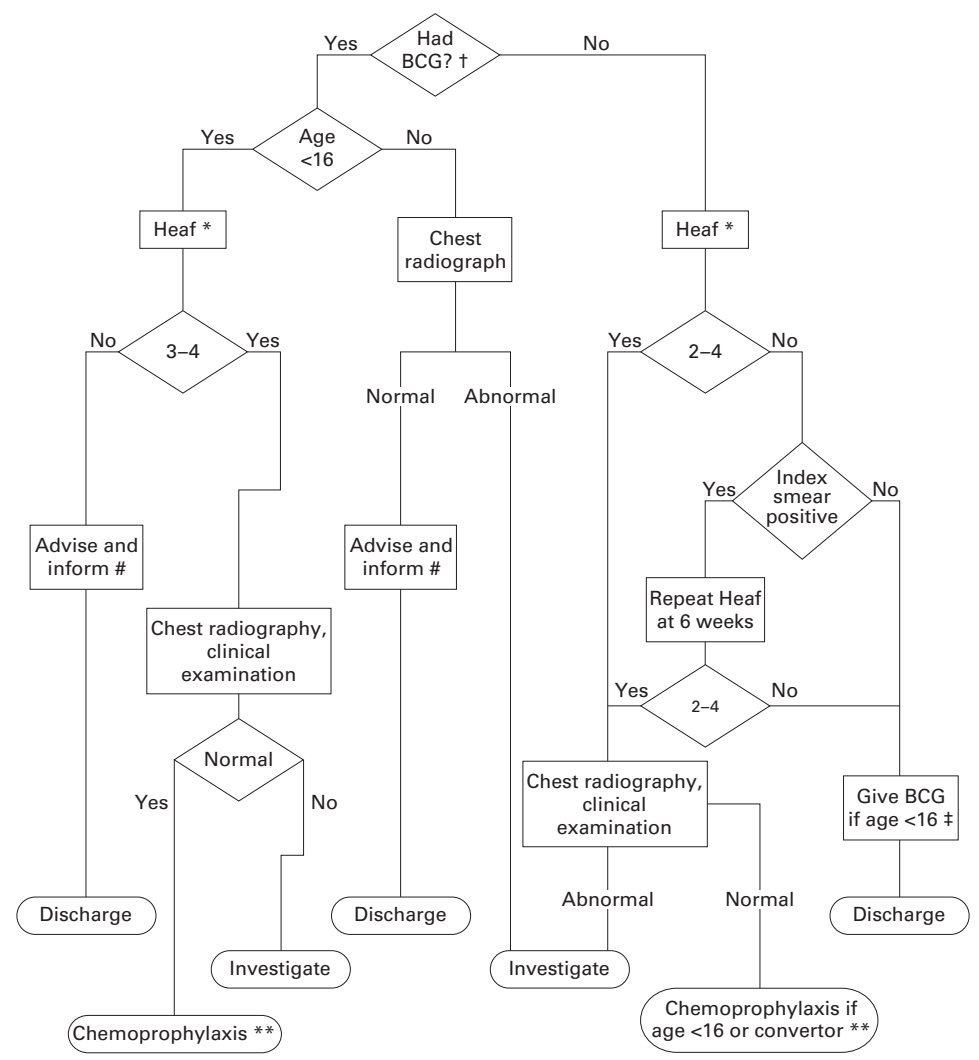

Figure 3 Contact tracing: examination of close contacts of patients with pulmonary tuberculosis. Contacts of patients with non-pulmonary tuberculosis need not usually be examined (see text). Note: children under two years who have not had a BCG vaccination who are close contacts of a smear positive index patient should receive chemoprophylaxis irrespective of tuberculin status (see text). +Previous BCG vaccination cannot be accepted as evidence of immunity in HIV infected subjects. ${ }^{\star} A$ negative test in immunocompromised subjects does not exclude tuberculous infection. \#Advise patient of tuberculosis symptoms and inform GP of contact. ${ }^{\star}$ Persons eligible for, but not given, chemoprophylaxis should have follow up chest radiographs at 3 and 12 months. $\neq$ See text.

Regional Tuberculosis Centres at Birmingham, Cardiff, and Newcastle.

\section{EXAMINATION OF CONTACTS}

It will not usually be known for how long the index patient has been infectious. We recommend review of contacts for the period of time that the patient has had respiratory symptoms including cough. If this is not known, contacts should be traced from three months preceding the first positive sputum smear or culture. Tracing should be extended backwards, usually a month at a time, if contact tracing yields higher than expected levels of tuberculin positivity/disease indicating transmission. ${ }^{58} \mathrm{In}$ vestigations of contacts (fig 3) may include inquiry into symptoms of tuberculosis, BCG vaccination status, Heaf testing, and chest radiography. Contacts with symptoms should be referred for rapid examination and assessment. If the index case is smear positive, contacts who have not had BCG vaccination and who have a negative or grade 1 positive Heaf reaction should ideally be retested six weeks after the last contact to allow time for tuberculin conversion. If retesting is not practicable, BCG vaccination should be given after the first negative Heaf test; chemoprophylaxis should also be given in children under two years of age. In HIV infected contacts a chest radiograph is essential because prior BCG vac- cination cannot be relied on as evidence of immunity and a negative tuberculin test may be due to anergy and does not exclude tuberculosis. The HIV status of an index case or contact, if known, must only be divulged with the patient's consent and all staff must ensure confidentiality during contact tracing procedures for tuberculosis.

\section{Management}

\section{BCG VACCINATION}

Evidence on the efficacy of BCG vaccination derives from studies in infants ${ }^{59}$ and schoolchildren. ${ }^{61}$ There are few data in adults to suggest that BCG vaccination offers protection if given over the age of $16,{ }^{28}{ }^{29}$ although absence of evidence does not mean absence of effect. However, BCG may be more effective in preventing tuberculous meningitis, which occurs particularly in young children, than in preventing pulmonary tuberculosis, ${ }^{62}$ hence the case for giving BCG is stronger in children than in adults. Furthermore, most contacts run a very low risk of continuing exposure to infection once the source case is treated effectively. ${ }^{12}$ For these reasons we recommend that BCG vaccination is only given to previously unvaccinated, persistently tuberculin negative (Heaf grade $0-1$ ) contacts under the age of 16 years, and should be offered to older contacts only if there are special occupational, ethnic, or travel risks. [B]

\section{CHEMOPROPHYLAXIS}

Chemoprophylaxis may be given to some contacts with strongly positive Heaf test reactions but no clinical or radiological evidence of tuberculous disease. The risk of developing disease after infection depends on the BCG status, HIV status, and whether infection is recent. Youth implies recent (or relatively recent) infection-and hence an increased likelihood of developing disease-and also a longer life expectancy for any benefit to be evident. Furthermore, the more serious forms of tuberculosis are seen more commonly in young children. We therefore recommend that chemoprophylaxis be given to the following groups: [B]

(1) Children aged $<16$ years with strongly positive Heaf tests (grades $2-4$ if no prior BCG, grades $3-4$ if prior BCG vaccination).

(2) Children aged $<2$ years in close contact with smear positive pulmonary disease:

(a) those without prior BCG vaccination

Give chemoprophylaxis irrespective of the initial Heaf test result. If the initial Heaf test is negative (grade $0-1$ ) repeat the test at six weeks and, if still negative, stop chemoprophylaxis and give BCG vaccination. If the repeat Heaf test result becomes positive (grades 2-4) give full chemoprophylaxis if chest radiography excludes disease. If the initial Heaf test is positive (grades 2-4) give full chemoprophylaxis if chest radiography excludes disease.

(b) those with prior BCG vaccination (confirmed by characteristic scar or vaccination record) 
If the initial Heaf test is strongly positive (grades 3-4) give full chemoprophylaxis if the chest radiograph excludes disease. If the Heaf test is grades $0-2$, repeat the test at six weeks. If there is no change in the reaction, no further action is required. If it has become positive (grades 3-4) give full chemoprophylaxis if the chest radiograph excludes disease.

(3) Those in whom recent tuberculin conversion has been documented.

(4) Babies born to mothers with infectious tuberculosis should receive chemoprophylaxis (normally with isoniazid syrup $5 \mathrm{mg}$ / $\mathrm{kg}$ ) for six weeks ${ }^{12}$ and then be tuberculin tested. If negative, BCG vaccination should be given and chemoprophylaxis stopped. If the tuberculin test is positive, chemoprophylaxis should be continued. ${ }^{12}$ Such babies may be breastfed.

(5) HIV infected close contacts of a patient with smear positive pulmonary disease.

RECOMMENDED CHEMOPROPHYLAXIS REGIMENS The recommendation made in the UK in $1998^{12}$ is for either isoniazid $(\mathrm{H})$ for six months $(6 \mathrm{H})$ or isoniazid and rifampicin $(\mathrm{R})$ for three months (3HR). The American Thoracic Society are now recommending a regimen of rifampicin (R) and pyrazinamide ( $\mathrm{Z}$ ) for two months (2RZ) instead of isoniazid for six months. ${ }^{63}$ The data to support $2 \mathrm{RZ}$ over $3 \mathrm{HR}$ are equivocal. In animal studies $\mathrm{RZ}$ and $\mathrm{HR}$ were equivalent but lower lung counts of organisms were obtained with HR. ${ }^{64}$ In studies in HIV infected individuals $2 \mathrm{RZ}$ performed as well as $6 \mathrm{H},{ }^{65}$ and $12 \mathrm{H}^{66}$ and $3 \mathrm{HR}$ performed as well as $6 \mathrm{H} .{ }^{67}$ In HIV infected individuals $3 \mathrm{HR}$ was as effective as $3 \mathrm{RZ}$ and $6 \mathrm{H},{ }^{68}$ and $3 \mathrm{HR}$ performed as well as $6 \mathrm{H}$ in high risk HIV negative individuals. ${ }^{69} 2 \mathrm{RZ}$ is less well tolerated than either $\mathrm{H}$ or $\mathrm{R},{ }^{70}{ }^{71}$ whereas $\mathrm{HR}$ is very well tolerated in children for three months or longer. ${ }^{73}$ Since $3 \mathrm{HR}$ is equally as effective as $2 \mathrm{RZ}$, is better tolerated than $2 \mathrm{RZ}$, and HR combination tablets are available for this regimen, the JTC continues to advise $3 \mathrm{HR}$ as an alternative regimen to $6 \mathrm{H}$. [B]

TIMING OF CONTACT TRACING

Close household contacts of a smear positive patient should be identified by the tuberculosis nurse or health visitor within two working days and seen within five working days of clinical diagnosis. In these circumstances a child contact under two years of age should be seen in the next clinic. Immunocompromised close contacts should also be seen urgently. If they are coughing, and are to be seen in a clinic with other immunocompromised patients, a sputum smear should be examined before they attend clinic or for a chest radiograph in order to reduce transmission opportunities. In general, procedures for close contacts should be completed within two weeks of notification of the index case except where repeat Heaf testing is required (fig 3).
FOLLOW UP

Most disease in contacts is found at initial examination. Those without evidence of disease at initial screening should be advised to report suspicious symptoms to their general practitioner who should also be advised of their contact with tuberculosis. Routine radiographic follow up at three and 12 months is now recommended only for those who are eligible for, but did not receive, chemoprophylaxis. ${ }^{52-54}$ HIV infected contacts should receive long term monitoring for tuberculosis as part of their routine follow up in HIV clinics. Coordination between the tuberculosis and HIV services is essential. General practitioners should be told of the patient's contact with tuberculosis and of the action/advice they have received. [B]

\section{Bovine tuberculosis}

Tuberculosis in cattle, as judged by positive tuberculin reactors and necropsy findings, is becoming more common in the UK. The rates are highest in south west England, parts of Wales, and the West Midlands. These events have given rise to increased requests for advice on the management of human contacts of cattle with tuberculosis. The overwhelming majority of the UK population is at negligible risk from Mycobacterium bovis infection because of milk pasteurisation. Cattle tuberculosis is almost entirely due to infection with $M$ bovis. In humans tuberculosis caused by $M$ tuberculosis and $M$ bovis can only be differentiated by laboratory diagnosis.

Surveillance of human $M$ bovis infection has been enhanced. The tuberculosis bacteriological reporting system of the Public Health Laboratory Service (Mycobnet) reported only 210 isolates of $M$ bovis from 1993 and $1997,{ }^{74}$ averaging 42 per year (approximately $1.0-1.5 \%$ of isolated $M$ tuberculosis complex), of which 200 cases were of white ethnic origin. Over three quarters were aged 50 years or more, suggesting reactivation of disease acquired earlier in life. Commercial molecular DNA or RNA based tests cannot differentiate between $M$ tuberculosis and $M$ bovis, reinforcing the need for bacteriological culture with referral of isolates for identification at the PHLS Mycobacterium Reference Unit, Regional Centres, or the Mycobacterium Reference Laboratory in Scotland. Non-commercial molecular methods exist for the identification of $M$ bovis such as spoligotyping or identification of mutations in the $p n c A$ gene. ${ }^{7576}$ Identification remains difficult; a recent outbreak of MDR-TB was initially identified as being caused by $M$ bovis but was subsequently confirmed as $M$ tuberculosis. ${ }^{77}$

Although tuberculosis can be diagnosed clinically, $M$ bovis is a bacteriological diagnosis. Where studies of human contacts of cattle have been undertaken, little evidence of transmission-as judged by tuberculin testing-and no clinical disease has been found. ${ }^{78}$ The advice on such contact tracing is therefore based largely on first principles and knowledge of the mechanisms of mycobacterial transmission (fig 4). Recent guidance has been 


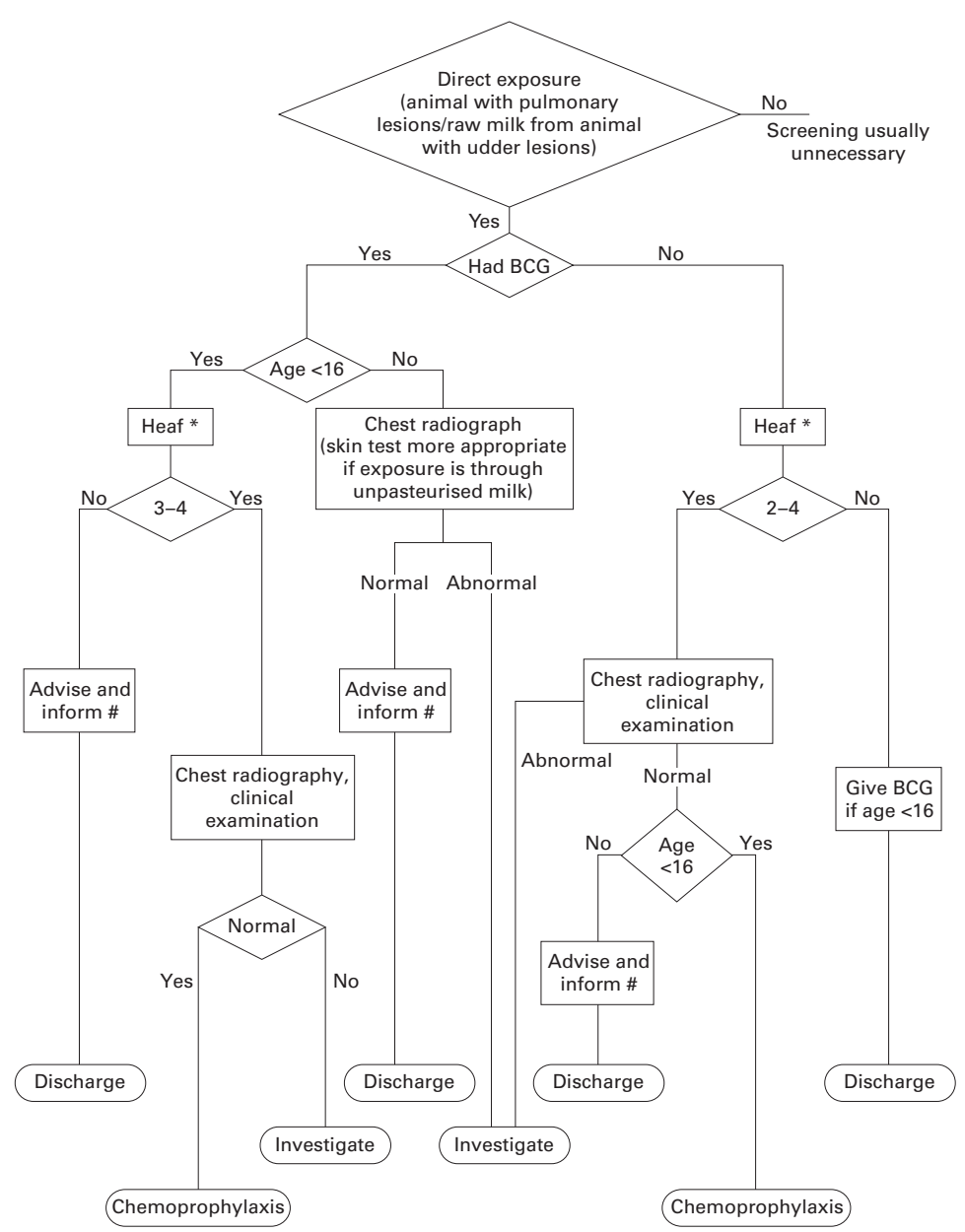

Figure 4 Contact tracing for contacts of cattle $M$ bovis infection. *At least 6 weeks after last exposure. \#Advise patient of tuberculosis symptoms and inform GP of contact.

issued by the Departments of Health. ${ }^{79}$ Contacts of human $M$ bovis infection should be managed as set out in fig 3 .

\section{Tuberculosis in aircraft}

Potentially infectious cases of tuberculosis are occasionally identified among people who have recently travelled by air. Follow up of passengers exposed to infectious cases has shown no case of active tuberculosis. Exposure on a long flight, however, appears to carry a very small risk of transmission of infection as determined by tuberculin conversions. The World Health Organisation (WHO) has recently published guidance intended to apply to all domestic and international airlines. ${ }^{80}$ The guidelines review the scientific evidence for the transmission of $M$ tuberculosis on aircraft and include a summary of seven investigations of potential transmissions of $M$ tuberculosis. They also discuss aircraft ventilation and air quality and the health of airline employees, and advise on how to reduce the risk of tuberculosis transmission. The risk to fellow travellers is small. The guidance recommends that action to contact passengers (and crew) should be taken when (1) the diagnosis has been confirmed; (2) the index case is smear positive and was symptomatic with cough at the time of the flight; (3) the duration of exposure was more than eight hours; and (4) it is less than three months since the flight. The action recommended is to inform passengers who sat in the same part of the aircraft of their potential exposure and of the need to seek advice from their family doctors. Most people can be reassured by their doctor but screening for tuberculosis infection or disease should be considered in particularly susceptible people such as young children or the immunocompromised, or if the index case is reported to be unusually infectious.

Identification of, and information to, the relevant passengers should be the responsibility of the airlines in liaison with the health authority in the area where the potentially exposed passengers live. The WHO does not recommend that further follow up, such as the determination of outcome of screening of passengers, should be carried out routinely. ${ }^{80}$

\section{Tuberculosis in schools}

Transmission of tuberculosis in schools is uncommon in the UK. Providing information to pupils, teachers, and parents is the most important element of the management of tuberculosis in schools so that the diagnosis may be considered early. Large lists of potential contacts are sometimes assembled for screening with considerable resource implications. False positive diagnoses of tuberculosis may occur in children due, for example, to infection with opportunist mycobacteria. Before embarking on programmes to examine substantial numbers of contacts, the diagnosis should usually be microbiologically confirmed by sending appropriate specimens for culture and/or molecular analysis. Primary specimens may be submitted to the PHLS Mycobacterium Reference Unit and the Scottish Mycobacterium Reference Laboratory for rapid molecular confirmation. It is sensible to identify groups in schools with more extensive contact with the case for screening in the first instance, following the "stone in the pond" principle. ${ }^{58}$ Examination may be extended to groups with a lesser degree of contact if evidence is found that the initial groups screened have been infected at a higher rate than expected. [B]

If the index case is a teacher and is sputum smear or culture positive, examination of children in the school who have been in direct contact with the case should be carried out - for example, classes/groups taught by the teacher. Younger contacts (primary schoolchildren up to the age of about 11 years) and any older children (secondary schoolchildren from about 11 years of age) who have not received BCG immunisation should be examined. Staff members and older children who have received BCG vaccination need only be examined if they are considered to be close contacts of the case.

Children with tuberculosis, even if they are smear positive, are rarely a source of infection. Nevertheless, if the index case is smear positive (a) all children, irrespective of BCG history, who have been close contacts (for example, same class or close friends) should be examined; and (b) in addition, any children who have not received BCG vaccination who have had casual contact (for example, in the same 
school year group or equivalent) should be examined. Only if step (b) shows evidence of transmission should screening of casual contacts with BCG vaccination be undertaken. Older children who have had BCG vaccination and staff members need not be examined unless they have been close contacts. Those screened should be managed as in fig 3 . If the index child has smear negative or nonpulmonary disease, no tracing of school contacts is required.

Child contacts who have not had BCG immunisation should ideally have a second tuberculin test six weeks after their last contact with the case. In practice, a single later tuberculin test may be a more practical approach provided that information about the proposed management of the incident and the need to be suspicious of otherwise unexplained illness has been given to pupils and parents.

Clusters of children with unexplained tuberculin sensitivity are often found in the course of the routine schools' BCG programme. ${ }^{81}$ In the absence of recognised tuberculosis cases, further investigation of these clusters is rarely fruitful. False positives are to be expected with a screening test and will form a large proportion of all positive tuberculin tests in the routine schools' programme in which the true prevalence of infection is very low. Clusters of false positives may occur as a result of problems of administration (wrong strength tuberculin, faulty injection technique) or interpretation (misreading of skin reactions), or because of common exposure to opportunist mycobacteria - for example, in drinking water. Further investigation of such clusters is only recommended if unusually high numbers of strongly positive reactors are observed or potentially related cases of disease have been identified. ${ }^{81}$

\section{Screening of immigrants}

The incidence of tuberculosis remains high in most ethnic minority groups in the UK, who now constitute over $50 \%$ of cases. ${ }^{32}$ The crude incidence per 100000 population in indigenous white residents in England in 1998 was 4.4 compared with 121 in Indian subcontinent, 210 in black African, and 26 in black Caribbean ethnic groups. ${ }^{3}$ The incidence of tuberculosis is highest in the first few years after first entry to the UK. ${ }^{3}{ }^{82}$ There is also evidence that subsequent return visits to countries with a high prevalence of tuberculosis is a risk factor. ${ }^{83} 84$ Screening of new immigrants is recommended as part of a coordinated local control policy. ${ }^{11}$ This not only detects those with clinical tuberculosis, but also identifies infected subjects, particularly children, who require chemoprophylaxis and uninfected subjects who may benefit from BCG vaccination. ${ }^{85} 86$ [B]

GROUPS TO BE SCREENED

The WHO has estimated the incidence of tuberculosis in different countries. ${ }^{87}$ An incidence of 40 per 100000 population per year is suggested as an arbitrary but reasonable level above which tuberculosis may be considered "common". ${ }^{11}$ In practice, this means that all immigrants (and other entrants planning to stay longer than six months such as university students) from all countries except current members of the European Union, Canada, United States, Australia, and New Zealand should be screened. In addition, all refugees should be screened. ${ }^{11}$

\section{PROCEDURES AT PORT OF ENTRY}

Most tuberculous disease develops after arrival in the UK and is not evident on arrival. ${ }^{85}{ }^{86}$ Initial reporting, with some limited screening, should take place at the port of arrival, but this system performs poorly with proportions of between $40 \%{ }^{85}$ and $60 \%{ }^{86}$ not being reported to the district of intended residence. It is essential that information on all new immigrants should be passed as rapidly as possible by the port of arrival to the CCDC or equivalent in the district of intended residence so that comprehensive local screening can occur. ${ }^{11}$

\section{PROCEDURES AT THE IMMIGRANT'S INTENDED} DISTRICT OF RESIDENCE

Health authorities should endeavour to identify all new immigrants, not only for tuberculosis screening but also for other relevant health promotion and disease protection measures. Because of the limited coverage of the official port of arrival system, ${ }^{8586} 88$ additional methods should be used to supplement detection-for example, through the health authority patient data register (Exeter system), applicants to register with a GP, records of new entrants to local schools, colleges and universities, and informal contacts with local immigrant voluntary and statutory agencies. The whole system is currently under review by the Interdepartmental Working Group on Tuberculosis.

Screening should consist of a health status interview including current symptoms, previous tuberculosis, and previous BCG vaccination. Tuberculin testing, preferably by Heaf testing, should be limited to those without a BCG scar. Screening and tuberculin testing should be carried out in the home or at a community hospital clinic at the convenience of the new immigrant. Consultation with local immigrant groups about these arrangements is advisable. [B]

Individuals with symptoms suggestive of tuberculosis and asymptomatic immigrants with strongly positive Heaf tests (Heaf grades $2-4$ in children under 16 , grades $3-4$ over 16 ) should be referred to a chest clinic for a clinical and radiographic examination. BCG vaccination should be offered to tuberculin negative children up to the age of 16 who have not previously received BCG. [B]

In the UK BCG immunisation has been shown to confer protection when given to neonates of Indian subcontinent origin ${ }^{59}{ }^{60}$ but no evidence of efficacy in adult immigrants is available. The incidence rate of tuberculosis in recent arrivals from high prevalence countries is very high shortly after arrival in the UK and, although it subsequently declines, it remains high for some years. ${ }^{382}$ In view of this high risk of disease, the JTC recommends that BCG 
immunisation be considered in tuberculin negative adult immigrants.

BCG immunisation is not recommended in anyone known or suspected to be HIV infected. ${ }^{36}$ The prevalence of HIV infection in some groups of new immigrants may be high. Tuberculin testing and policies for offering BCG immunisation should take local HIV prevalence rates into account.

Chemoprophylaxis should be given to children under 16 (Heaf grade 2 or greater) and considered in young adults (age16-34 years) with grade 3-4 positive Heaf tests. ${ }^{12}$ If chemoprophylaxis is not given, the patient and the general practitioner should be advised of symptoms that can suggest tuberculosis and the need to report them. The same advice should be given to older adults with strongly positive tuberculin tests. [B]

\section{Outbreak investigation}

The investigation of a suspected outbreak of tuberculosis, as with other infectious disease outbreaks, ${ }^{89}{ }^{90}$ requires the input of a multidisciplinary team including the local CCDC as the lead, clinicians, microbiologists, tuberculosis nurses, and others such as the hospital control of infection officer, depending on the setting. Further advice on the management of the incident should be sought from the PHLS regional epidemiologist and Communicable Disease Surveillance Centre (Scottish Centre for Infection and Environmental Health in Scotland), from the PHLS Regional Centres for Mycobacteriology and Mycobacterium Reference Unit on microbiological issues, and from clinicians with special expertise in tuberculosis on clinical issues. Confirmation of the diagnosis is essential, although some infection control and other public health action may be necessary on the basis of a presumed diagnosis. The use of molecular methods to obtain a rapid confirmation of diagnosis is usually justified in these circumstances.

Cases of tuberculosis occurring as part of an outbreak can be linked using molecular epidemiological or DNA fingerprinting techniques, provided that they are bacteriologically proven. The PHLS Mycobacterium Reference Unit provides a national molecular epidemiological service using an internationally standardised system of restriction fragment length polymorphism (RFLP) based on the insertion sequence IS6110. ${ }^{91}$ Cultures of $M$ tuberculosis from the relevant individuals should be submitted by the local laboratory to the Mycobacterium Reference Unit with each isolate accompanied by a completed molecular epidemiology form (available from the Mycobacterium Reference Unit). Techniques using molecular amplification are available to evaluate linkage more rapidly than RFLP on submitted cultures and under certain circumstances on smear positive sputum specimens, but they are not as discriminatory as the IS6110 technique. ${ }^{759293}$ Great care must be taken in interpreting the results of rapid PCR based techniques which are simpler to perform than RFLP as several techniques have poor reproducibility and/or discrimination and are likely to produce misleading results. ${ }^{94}$ DNA fingerprinting can provide strong evidence of transmission, it does not provide absolute proof, and should be interpreted in conjunction with conventional epidemiology wherever possible. [B]

\section{BCG immunisation}

National policy ${ }^{95}$ is that BCG vaccination should be offered to all children between the ages of 10 and 14 years and to certain groups at higher risk of exposure to tuberculosis. These include infants and children of immigrants from countries with a high prevalence of tuberculosis and children born to adults born in the UK but from ethnic groups originating in high prevalence countries. Although rates of tuberculosis are lower among such adults in the UK, they are still generally above 40 per 100000 population (PHLS unpublished data from the 1998 National Tuberculosis Survey in England and Wales) compared with approximately 10 per 100000 in the overall population.

Neonates and infants up to the age of three months who have no known contact with tuberculosis may be offered BCG immunisation without prior tuberculin testing. Older infants and children should undergo tuberculin testing before BCG immunisation. School entry is an opportunity to give BCG immunisation to children in this group who have missed it previously. Neonatal BCG vaccination is effective ${ }^{5960}$ and can be given by intradermal injection or by the multiple puncture percutaneous method..$^{95}$ [B]

The policy in the UK is still that BCG vaccination should be routinely offered in schools to all children aged $10-14$ years. ${ }^{95}$ It was thought at one time that the schools' BCG programme might be discontinued at the end of the 1980s. The rise in tuberculosis notifications after 1987, continuing uncertainty about the effect of the global HIV pandemic and its effect on the UK, and the lack of sufficient data to be certain that the decline in tuberculosis was continuing in the groups relevant to the schools' BCG programme ${ }^{82}$ led to the recommendation that the schools' programme be continued. ${ }^{96}$

The International Union against Tuberculosis and Lung Disease has recommended criteria for the discontinuation of routine BCG programmes in countries with a low prevalence of tuberculosis, ${ }^{97}$ which state that there should be a reliable reporting system for tuberculosis over the previous 3-5 years to enable the estimation of active tuberculosis by age and risk groups with particular emphasis on tuberculous meningitis and sputum smear positive pulmonary disease. The schools' programme in England and Wales will continue until detailed epidemiological information from the 1998 national tuberculosis survey and subsequent continuous enhanced surveillance is available. Whatever the ultimate decision on the schools' programme, it should not affect the policy for high risk groups - that is, health care workers at risk, young tuberculin negative contacts, tuberculin negative immigrants from countries where tuberculosis is common, and infants in high prevalence ethnic groups. 
Because of the risk of generalised BCG infection, BCG vaccination should not be given to individuals known to be HIV infected in the UK. ${ }^{98}$ When HIV infection is suspected in infants or in tuberculin negative contacts of tuberculosis, HIV testing should be undertaken and BCG vaccination only given to those confirmed to be HIV negative. [B]

In the schools' BCG programme tuberculin testing is not necessary in those with a definite BCG scar or documented history of prior BCG immunisation since, whatever the result, they will not be receiving a further BCG vaccination. In the children who are to be tested, those with Heaf grades $0-1$ should be vaccinated. No action is recommended for those with Heaf grade 2 . In an area with an unusually high prevalence of tuberculosis, referral of children with grade 2 reactions has been advocated ${ }^{99}$ but the evidence for the effectiveness of this approach is limited and the yield of cases very low ${ }^{100}{ }^{101}$; the approach is not generally recommended.

Those with Heaf grades 3 and 4 should be referred for clinical and radiographic examination. If these are normal, chemoprophylaxis is recommended for those with a history of contact with infectious tuberculosis or residence in a high prevalence area within the preceding two years, and should be considered for others in high risk groups.

\section{Appendix}

DRAFT LETTER FOR GENERAL PRACTITIONERS AND CONSULTANTS

Dear Dr X,

Your patient $\mathrm{Y}$ was an inpatient at this hospital at the same time as another patient with potentially infectious tuberculosis.

We do not think it likely that your patient is at significant risk of infection, and no specific action need be taken unless you are aware that they are unusually susceptible to infectious disease.

In the very unlikely event of your patient consulting you in the future with persistent symptoms which are consistent with the diagnosis of tuberculosis, then you will wish to keep this possible exposure to the disease in mind. The patient has been advised of the exposure.

Yours sincerely

DRAFT LETTER FOR PATIENTS PRESENT ON THE SAME WARD AS A CASE OF INFECTIOUS TUBERCULOSIS

Dear X,

During a recent stay in our hospital there was a patient on $\mathrm{Y}$ ward who has been diagnosed as having tuberculosis.

It is routine procedure for us to inform individuals like yourself who may have potentially come into contact with the person with tuberculosis, and this information has also been passed on to your consultant and general practitioner. We do not believe that you are at any significant risk and no further action need be taken.

If you do have any particular concerns or believe yourself to be at particular risk of infectious disease, you can discuss this with your doctor.

Yours sincerely

1 Joint Tuberculosis Committee of the British Thoracic Society: Code of Practice 1994. Thorax 1994;49:1193-200.

2 Ormerod LP, Charlett A, Gilham C, et al. Geographical dis-

Ormerod LP, Charlett A, Gilham C, et al. Geographical dis-
tribution of tuberculosis notifications in national surveys of tribution of tuberculosis notifications in national surveys of England
3 Rose AMC. 1998 National TB Survey in England and Wales: final results. Thorax 1999;54(Suppl 3):A5.

4 Irish C, Herbert J, Bennett D, et al. Database study of antibiotic resistant tuberculosis in the United Kingdom, 1994-6. BMF 1999;318:497-8.

5 Petrie JG, Barnwell E, Grimshaw J, on behalf of the Scottish Intercollegiate Guidelines Network. Clinical guidelines: criteria for appraisal for national use. Edinburgh: Royal College of Physicians, 1995.

6 Agency for Health Care Policy and Research. Acute pain management, operative or medical procedures and trauma. Clinical practice guideline 92-0032. Rockville, Maryland: Agency for Healthcare Policy and Research Publications, 1992.

7 Ormerod LP, Watson JM, Pozniak A, et al. Notification of tuberculosis: an updated code of practice for England and Wales. F R Coll Phys London 1997;31:299-303.

8 Ferguson A, Bennett D, Conning S. Notification of Ferguson A, Bennett D, Conning S. Notification of
tuberculosis in patients with AIDS. $\mathcal{f}$ Publ Health Med 1998;20:218-20.

9 Sheldon CD, King K, Cock H, et al. Notification of tuberculosis: how many cases are never reported? Thorax 1992;47:1015-8.

10 Public Health (Control of Disease) Act 1984. Sections 35, 37 and 38.

11 The Interdepartmental Working Group on Tuberculosis. Recommendations for the control and prevention of tuberculosis at local level. Department of Health and Welsh Office, June 1996.

12 Joint Tuberculosis Committee of the British Thoracic Society. Chemotherapy and management of tuberculosis in the United Kingdom: recommendations 1998. Thorax 1998;

13 United Kingdom Central Council for Nursing, Midwifery and Health Visiting (UKCC). A higher level of practice: draft descriptor and standard. 1999.

14 Williams C, Jamieson S. Community based control in developed countries. In: Davies PDO, ed. Clinical tuberculosis 2nd ed. London: Chapman and Hall, 1998: 485-96.

15 Ormerod LP. Audit of TB nurse and secretarial provision in high incidence districts. Thorax 1999;54(Suppl 3):A49.

16 Connolly M. A survey of workload, resources and work practices among TB nurses in london. On behalf of the London TB Nurse Network, 1999.

17 Chan S, Yew W. Chemotherapy. In: Davies PDO, ed. Clinical tuberculosis 2nd ed. London: Chapman and Hall, 1998: 243-63.

18 The Interdepartmental Working Group on Tuberculosis. The prevention and control of tuberculosis in the United Kingdom: UK guidance on the prevention and control of transmission of 1 . HIV-related tuberculosis 2. Drug-resistant, including multiple drug-resistant, tuberculosis. Department of Health, The Scottish Office, The Welsh Office, September 1998 .

19 George RH, Gully PR, Gill ON, et al. An outbreak of tuberculosis in a children's hospital. F Hosp Infect 1986;8:12942 .

20 Jindani A, Aber VR, Edwards EA, et al. The early bactericidal activity of drugs in patients with pulmonary tuberculosis. Am Rev Respir Dis 1980;121:139-48.

21 Rouillon A, Predizet S, Parrot R. Transmission of tubercle bacilli: the effects of chemotherapy. Tubercle 1976;57:27599.

22 Riley RL, Moodie AS. Infectivity of patients with tuberculosis in inner city homes. Am Rev Respir Dis 1974;110:810-2.

23 Brindle RI, Nunn PP, Githui W, et al. Quantitative bacillary response to treatment in HIV-associated pulmonary tuberculosis. Am Rev Respir Dis 1993;147:958-61.

24 Perriens JH, St Louis ME, Yiadiul B, et al. Pulmonary tuberculosis in HIV-infected patients in Zaire. N Engl Med 7 1995;332:779-84.

25 Lunn JA, Mayho V. Incidence of pulmonary tuberculosis by occupation of hospital employees in the National Health Service in England and Wales 1980-84. F Soc Occup Med 1989;39:30-2.

26 Meredith S, Watson JM, Citron KM, et al. Are healthcare workers in England and Wales at increased risk of tuberculosis? BMF 1996;313:522-5.

27 Cockcroft A, Chapman S, Insall C, et al. Tuberculin recativity in new employees in a London health district. Thorax 1988;43:834.

28 Springett VH, Sutherland I. A re-examination of the variations in efficacy of BCG vaccination against tuberculosis in clinical trials. Tuberc Lung Dis 1994;75:227-33.

29 Brewer TF, Colditz GA. Bacille-Calmette-Guerin vaccination for the prevention of tuberculosis in health care workers. Clin Infect Dis 1995;20:136-42.

30 Chaturvedi N, Cockcroft A. Tuberculosis screening among health service employees: who needs chest X-rays? $\mathcal{F}$ Soc Occup Med 1992;42:179-82.

31 Burge A, Kumar S, Skinner C. Control of tuberculosis in NHS staff: West Midlands 1990-92. Thorax 1993;48:463.

32 Madan I. Pre-employment chest X-rays for health service staff: who needs them? BMF 1993;306:1041-2.

33 Cockcroft A. Pre-employment chest radiography and NHS staff. BMF 1993;306:1286

34 Capewell S, Leaker AR, Leitch AG. Tuberculosis in NHS staff: is it a problem? Thorax 1986;41:708.

35 United Kingdom Health Departments. Guidance on the management of AIDS-HIV infected health care workers and patient notification. December 1998.

36 Departments of Health, Joint Committee on Vaccination and Immunisation. Immunisation against disease. London: HMSO, 1996. 
37 Breathnach AS, De Ruiter A, Holdsworth GM, et al. An outbreak of multi-drug-resistant tuberculosis in a London teaching hospital. F Hosp Infect 1998;39:111-7.

38 The first report of the Director of Health Care of Prisoners. HM Prison Service, 1993

39 Ross-Plummer R, Sridhar MK. Tuberculosis prevention amongst prison staff: are BTS recommendations implemented? Thorax 1999;54(Suppl 3):A51.

40 The future organisation and delivery of prison health care. Health Service Circular 1999/077.

41 Stead WW, Lofgren JP, Warren E, et al. Tuberculosis as an endemic and nosocomial infection among the elderly in nursing homes. N Engl F Med 1985;312:1483-7.

42 Nisar M, Williams CSD, Ashby D, et al. Tuberculin testing in residential homes for the elderly. Thorax 1993;48:125760.

43 Kumar D, Citron KM, Leese J, et al. Tuberculosis among the homeless at a temporary shelter in London: a report of chest X-ray screening programme. 7 Epidemiol Community Health 1995;49:629-33.

44 Citron KM, Southern A, Dixon M. Out of the shadow. London: Crisis, 1995.

45 The Interdepartmental Working Group on Tuberculosis The prevention and control of tuberculosis in the United Kingdom: tuberculosis and homeless people. Department of Health and the Welsh Office, June 1996.

46 Kenyon TA, Valway SE, Ihle MPA, et al. Transmission of multidrug-resistant Mycobacterium tuberculosis during a long airplane flight. $N$ Engl f Med 1996;334:933-8.

47 Hussain SF, Watura R, Cashman B, et al. Tuberculosis contact tracing: are the British Thoracic Society Guidelines still appropriate? Thorax 1992;47:984-5.

48 Esmonde TGF, Petheram IS. Audit of TB contact tracing procedures in South Gwent. Respir Med 1991;85:421-4.

49 Teale C, Cundall DB, Pearson SB. Time of development of tuberculosis in contacts. Respir Med 1991;85:475-7.

50 Ormerod LP. Tuberculosis contact tracing: Blackburn 1982-90. Respir Med 1992;87:127-31.

51 Kumar S, Innes JA, Skinner C. Yield from tuberculosis contact tracing in Birmingham. Thorax 1992;47:875.

52 Ansari A, Thomas S, Campbell IA, et al. Refined tuberculosis contact tracing in a low incidence area. Respir Med 1998;92:1127-31.

53 Irish C, Jolly E, Baker T, et al. Contract tracing smear negative and non-pulmonary tuberculosis in a high incidence area. Thorax 1997;52(Suppl 6):A34.

54 Hardinge FM, Black $M$, Chamberlain $\mathrm{P}$, et al. TB contact tracing in South Buckinghamshire from 1994 to mid 1998 Am 7 Respir Crit Care Med 1999;159:A303.

55 Behr MA, Warren SA, Salamon $\mathrm{H}$, et al. Transmission of Mycobacterium tuberculosis from patients smear-negative for acid-fast bacilli. Lancet 1999;353:444-9.

56 Grzybowski S, Barnett GD, Styblo K. Contacts of cases of active pulmonary tuberculosis. Bull Int Union Tuberc 1975; 50:90-106.

57 Stoddart $\mathrm{H}$, Noah $\mathrm{N}$. Usefulness of screening large numbers of contacts for tuberculosis: questionnaire based review. of contacts for tub
BMF 1997;315:651.

58 Veen J. Microepidemics of tuberculosis: the stone in the pond principle. Tuberc Lung Dis 1992;73:73-6.

9 Rodrigues LC, Gill ON, Smith PG. BCG vaccination in the first year of life protects children of Indian subcontinent ethnic origin against tuberculosis in England. 7 Epidemio Community Health 1991;45:75-80.

60 Packe GE, Innes JA. Protective effect of BCG vaccination in infant Asians: a case control study. Arch Dis Child 1988;63 277-81.

61 Hart PD, Sutherland I. BCG and vole bacillus vaccines in the prevention of tuberculosis in adolescence and early adult life. BMF 1977;2:293-5.

62 Rodrigues LC, Diwan VK, Wheeler JG. Protective effect of BCG against tuberculous meningitis and miliary tuberculosis: a meta-analysis. Int $f$ Epidemiol 1993;22: 1154-8.

63 American Thoracic Society and Centres for Disease Control and Prevention. Targeted tuberculin testing and treatment of latent tuberculosis infection. Am f Respir Crit Care Med. 2000 (in press).

64 Dillon J, Dickinson JM, Sole K, et al. Preventive chemotherapy of tuberculosis in Cornell model mice with combi-
nations of rifampin, isoniazid, and pyrazinamide. Antiminations of rifampin, isoniazid, and p
crob Agents Chemother 1996;40:552-5.

65 Halsey NA, Coberly JS, Desormeaux J, et al. Randomized trial of isoniazid versus rifampin and pyrazinamide for prevention of tuberculosis in HIV-1 infection. Lancet 1998; 351:786-92.

66 Gordin FM, Chaisson RE, Matts JP, et al. An international, randomized trial of rifampin and pyrazinamide versus isoniazid for prevention of tuberculosis in HIV-infected persons (submitted for publication).

67 Mwinga A, Hosp M, Godfrey-Faussett P, et al. Twice weekly tuberculosis preventive therapy in HIV infection in Zambia. AIDS 1998;12:2447-57.

68 Whalen CC, Johnson JL, Okwera A, et al. A trial of three regimens to prevent tuberculosis in Ugandan adults infected with the human immunodeficiency virus. $N$ Engl Med f 1997;337:801-8.

69 Hong Kong Chest Service, Tuberculosis Research Centre Madras, and British Medical Research Council. A doubleblind placebo-controlled clinical trial of three antituberculosis chemoprophylaxis regimens in patients with silicosis in Hong Kong. Am Rev Respir Dis 1992;145:36-41.
70 Geiter LJ, O'Brien RJ, Kopanoff DE. Short-course preventive therapy for tuberculosis. Am Rev Respir Dis 1990;141: A437.

71 Geiter LJ. Results of a randomized, controlled trial to assess the toxicity and patient adherence with two short-course regimens for the prevention of tuberculosis, a two-month regimen of rifampin and pyrazinamide and a four-month egimen of rifampin only, in comparison with a control regimen of six-months isoniazid. Disertation thesis submitted to Johns Hopkins University, School of Hygiene and Public Health, Baltimore, Maryland, 1997.

72 Ormerod LP. Rifampicin and isoniazid prophylactic chemotherapy for tuberculosis. Arch Dis Child 1998;78:169-71.

73 Ormerod LP. Reduced incidence of paediatric tuberculosis following prophylactic chemotherapy in strongly tuberculin positive children. Arch Dis Child 1987;62:1005-8.

74 Public Health Laboratory Service. Enhanced surveillance of Mycobacterium bovis in humans. Communicable Disease : $281-4$.

75 Kamerbeek J, Schouls L, Kolk A, et al. Rapid detection and simultaneous strain differentiation of Mycobacterium tuberculosis for rapid diagnosis and tuberculosis control. 7 Clin Microbiol 1997;35:907-14

76 Scorpio A, Zhang Y. Mutations in pncA, a gene encoding pyrazinamidase/nicotinamidase cause resistance to the antituberculosis drug pyrazinamide in tubercle bacillus. Nature Med 1996;2:662-7.

77 Gutierrez MC, Galan JC, Blazquez J, et al. Molecular markers demonstrate that the first described multi-drug resistant Mycobacterium bovis outbreak was due to $\mathrm{Myco-}$ bacterium tuberculosis. F Clin Microbiol 1999;37:971-5.

78 Cawthorne D, Raashed M, Synnott M, et al. Contact tracing in bovine TB. Eur Respir f 1997;11: P1388.

79 World Health Organisation. Tuberculosis and air travel: guidelines for prevention and control. Report WHO/TB/98.256. Geneva: WHO, 1998.

80 United Kingdom Departments of Health. Guidance on the management of the public health consequences of tuberculosis in management of the public health consequences of tuberculosis in

81 Outbreak forum IV. High prevalence of tuberculin sensitivity. Communicable Disease Report 1992;1: R67-9.

82 Kumar D, Watson JM, Charlett A, et al. Tuberculosis in England and Wales in 1993: results of a national survey. Thorax 1997;52:1060-7.

83 McCarthy OR. Asian immigrant tuberculosis: the effect of visiting Asia. Br f Dis Chest 1984;78:248-53.

84 Ormerod LP, Green RM, Gray S. Are there still effects on tuberculosis of visiting the Indian subcontinent: a longitudinal study 1978-97. Thorax 1999;54(Suppl 3): A50.

85 Ormerod LP. Tuberculosis screening and prevention in new immigrants 1983-88. Respir Med 1990;84:269-71.

86 Ormerod LP. Is immigrant screening for tuberculosis still worthwhile? f Infect 1998;37:39-40.

87 World Health Organisation. Global tuberculosis control. WHO report WHO/CDS/CPC/TB/99.259. Geneva: World Health Organisation, 1999

88 Hardie RM, Watson JM. Screening migrants at risk of tuberculosis. BMF 1993;307:1539-40.

89 Palmer SR. Epidemiology in search of infectious disease: methods in outbreak investigation. $F$ Epidemiol Community Health 1989;43:311-4.

90 Reingold AL. Outbreak investigations: a perspective. Emergency Infect Dis 1998;4:21-7.

1 Van Sollingen D, De Haas PEW, Herrans PWM, et al. Comparison of various repetitive DNA elements as genetic markers for strain differentiation and epidemiology of 95.

92 Haas WH, Butler WR, Woodley CL, et al. Mixed-linker polymerase chain reaction: a new method for rapid fingerprinting of isolates of the Mycobacterium

93 Wilson SM, Goss S, Drobniewski F. Evaluation of strategies for molecular fingerprinting in use in the routine work of a Mycobacterium Reference Unit. 7 Clin Microbiol 1998;36: 3385-8.

94 Kremer $\mathrm{K}$, Van Soolingen D, Frothingham $\mathrm{R}$, et al. Comparison of methods based on different molecular epidemiological markers for typing of Mycobacterium tuberculosis complex strains: interlaboratory study of discriminatory power and reproducibility. F Clin Microbiol 1999;37: $2607-18$.

95 United Kingdom Health Departments. Immunisation against infectious disease. London: HMSO, 1996.

96 Department of Health. Tuberculosis: two reports from the Interdepartmental Working Group on Tuberculosis. Executive Letter EL(96) 51, July 1996.

97 International Union against Tuberculosis and Lung Disease. Criteria for discontinuation of vaccination programmes using Bacille Calmette-Guerin (BCG) in countries with a low prevalence of tuberculosis. Tuberc Lung Dis 1994;75:179-81.

98 Subcommittee of the Joint Tuberculosis Committee. Guidelines on the management of tuberculosis and HIV infection in the United Kingdom. BMF 1992;284:1454-6.

99 Booth H, Pollitt C, Jessen EC, et al. When is referral of Heaf test positive schoolchildren worthwhile? Prospective study. BMF 1996;313:726-7

100 Elliman D. When is referral of Heaf test positive schoolchildren worthwhile? BMF 1996;314:71

101 Packe GE. When is referral of Heaf test positive schoolchildren worthwhile? BMF 1996;314:71-2. 